Jurnal Pemberdayaan: Publikasi Hasil Pengabdian kepada Masyarakat

Vol. 2, No. 1, April 2018, Hal. 135-142

ISSN: 2088 4559; e-ISSN: XXXX-XXXX

DOI:

\title{
PEMBERDAYAAN MASYARAKAT BAUSASRAN YOGYAKARTA DALAM PROGRAM PEDULI LINGKUNGAN, KEBERSIHAN DAN KESEHATAN
}

\author{
Iis Wahyuningsih ${ }^{1}$, Muhammad Riski Pratama ${ }^{2}$ \\ ${ }^{1,2}$ Universitas Ahmad Dahlan, Kampus 3, Jl. Prof. Dr. Supomo, Janturan, Yogyakarta \\ Email: iis.wahyuningsih@pharm.uad.ac.id
}

\begin{abstract}
ABSTRAK
Beberapa permasalahan yang ditemukan di masyarakat Kelurahan Bausasran, Kecamatan Danurejan, Kota Yogyakarta yaitu kurangnya lahan hijau, kurangnya kesadaran masyarakat terhadap kebersihan lingkungan, dan kurangnya kemampuan masyarakat dalam memanfaatkan sampah. Maka program Kuliah Kerja Nyata (KKN) Universitas Ahmad Dahlan (UAD) bersama dosen pebimbing lapangan (DPL) difokuskan kepada upaya peningkatan kepedulian terhadap lingkungan dan kesehatan. Program ini bertujuan memberdayakan masyarakat kampung Lempuyangan Bausasran dalam program peduli lingkungan, kebersihan dan kesehatan. Metode pelaksanaan program KKN UAD ini meliputi : pendidikan masyarakat, difusi teknologi dan praktek langsung. Dampak dari kegiatan KKN ini adalah: 1) peningkatan kesadaran masyarakat sasaran tentang pentingnya Pola Hidup Bersih dan Sehat, 2) peningkatan pengetahuan masyarakat dalam mengolah sampah, 3) tersedianya lahan hijau untuk produktifitas masyarakat, 4) tercipta kesadaran masyarakat tentang kebersihan dan kesehatan di lingkungan sekitar.
\end{abstract}

Kata kunci : pemberdayaan, Lempuyangan, Bausasran, peduli lingkungan, kebersihan, kesehatan

\begin{abstract}
There are several problems that exist in the community of Bausasran Village, Danurejan District, Yogyakarta City such as lack of green lands, lack of public awareness of environmental cleanliness, and lack of the community's ability to utilize waste. Therefore, the Ahmad Dahlan University Community Service Program with the field supervisors (DPL) focused on the efforts to increase environmental and health care. This program aims to empower the Lempuyangan Bausasran village community in an environment care program, hygiene and health. The methods for implementing the UAD KKN program include: community education, technology diffusion and direct practice. The impacts of the KKN activities are: 1) increasing awareness of the target community about the importance of a Clean and Healthy Lifestyle, 2) increasing community knowledge in recycling waste, 3) the availability of green lands for the community productivity, 4) creating a public awareness about hygiene and health in the environment around.
\end{abstract}

Keywords:: empowerment, Lempuyangan, Bausasran, caring for the environment, cleanliness, health 


\section{PENDAHULUAN}

Luas wilayah kelurahan Bausasran 0,47 km². Jumlah penduduk di kelurahan Bausasran sebanyak 7.341 orang terdiri dari 3.576 penduduk laki-laki dan 3.765 penduduk perempuan. Berdasar usia, penduduk Bausasran terbagi menjadi: usia 0 - 15 tahun sebanyak 1.686 jiwa, usia 15 - 65 tahun sebanyak 5.163 jiwa, dan usia 65 tahun ke atas sebanyak 492 jiwa. Komposisi penduduk berdasarkan usia dan persentasinya dapat dilihat gambar 1 .

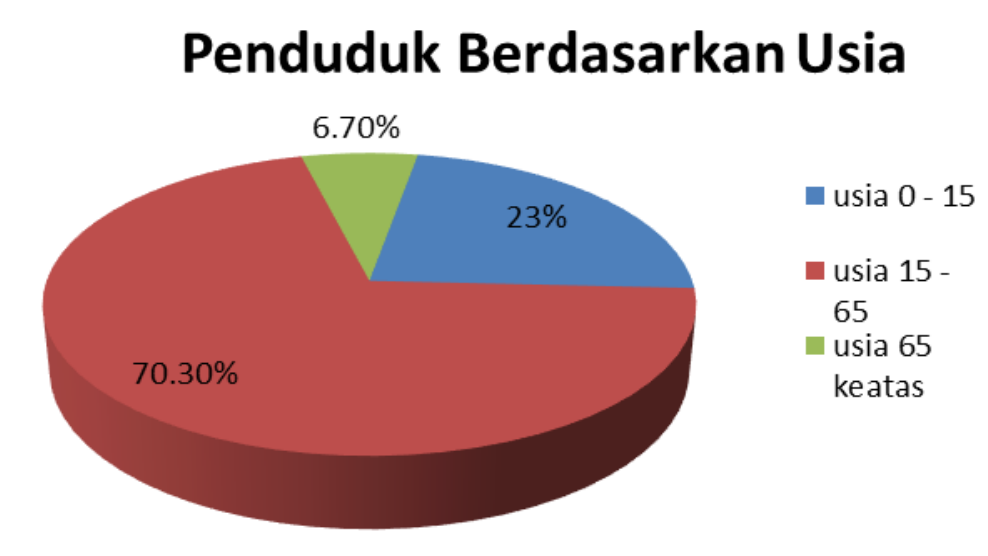

Gambar 1. Komposisi penduduk Bausasran berdasarkan usia

Komposisi penduduk berdasar pekerjaan yaitu PNS sebanyak 239 orang, ABRI sebanyak 15 orang, swasta sebanyak 1.703 orang, wiraswasta sebanyak 130 orang, tani 8 orang, pertukangan sebanyak 22 orang, pensiunan sebanyak 179 orang, dan jasa sebanyak 1.031 orang. Komposisi penduduk berdasarkan pekerjaan dan persentasinya dapat dilihat dalam gambar 2.

Komposisi penduduk berdasar tingkat pendidikan masyarakat yaitu Taman KanakKanak 193 orang, Sekolah Dasar 661 orang, SMP 871 orang, SMA/SMU 2.341 ORANG, Akademi/D1-D3 445 orang, Sarjana 1.351 orang dan Pasca Sarjana 142 orang .Komposisi penduduk berdasar tingkat pendidikan tersaji pada gambar 3. 


\section{Penduduk Berdasar Pekerjaan}

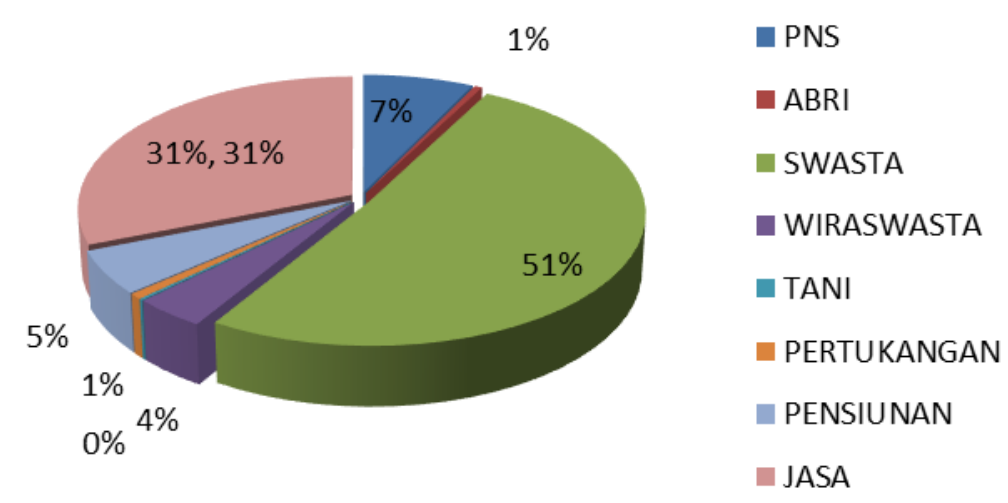

Gambar 2. Komposisi penduduk Bausasran berdasar pekerjaan

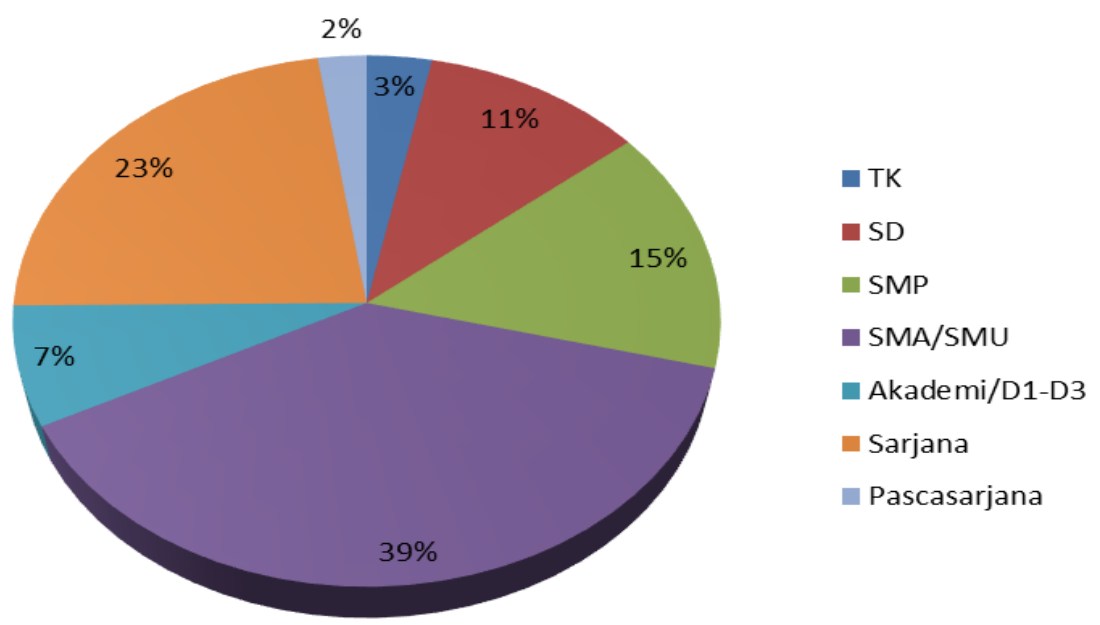

Gambar 3. Komposisi penduduk Bausasran berdasar tingkat pendidikan

Beberapa permasalahan yang ditemukan pada warga Kelurahan Bausasran Kecamatan Danurejan adalah: 1) Pemukiman penduduk yang cukup padat, 2) pengolahan lahan yang belum tertata, 3) kurangnya pengetahuan masyarakat dalam memilah dan memanfaatkan sampah organik dan anorganik. 4) kurangnya keterampilan masyarakat dalam memanfaatkan sampah yang masih memiliki nilai guna, 5) kurangnya pengetahuan 
masyarakat tentang PHBS, 6) kurangnya pengetahuan masyarakat tentang kepedulian lingkungan sekitar dan kesehatan.

Peran serta masyarakat dalam pengelolaan lingkungan merupakan kesediaan masyarakat untuk membantu berhasilnya program pengembangan pengelolaan lingkungan sesuai dengan kemampuan setiap orang tanpa mengorbankan kepentingan diri sendiri (Azwar, 2005. Tanpa adanya peran serta masyarakat semua program pengelolaan persampahan yang direncanakan akan sia-sia (Artiningsih, 2008). Terdapat beberapa cara pendekatan masyarakat untuk dapat membantu program pemerintah, yang pertama dalam keberhasilan adalah membiasakan masyarakat pada tingkah laku yang sesuai dengan program persampahan yaitu merubah persepsi masyarakat terhadap pengelolaan sampah yang tertib, lancar dan merata, merubah kebiasaan masyarakat dalam pengelolaan sampah yang kurang baik dan faktor-faktor sosial, struktur dan budaya setempat (Wibowo dan Djajawinata, 2004). Menurut Syafrudin (2004), salah satu alternatif yang bisa dilakukan adalah melaksanakan program pengelolaan sampah berbasis masyarakat, seperti minimalisasi limbah dan melaksanakan 5 R (Reuse, Recycling, Recovery, Replacing dan Refilling). Dan yang kedua menerapkan peraturan yang dikeluarkan oleh pemerintah, yaitu Peraturan Walikota Yogyakarta Nomor 5 Tahun 2007 tentang Pengelolaan Ruang Terbuka Hijau dan Peraturan Walikota Yogyakarta Nomor 6 Tahun 2010 tentang Penyediaan Ruang Terbuka Hijau Privat. Sosialisasi dan pelatihan masyarakat terhadap program pemerintah tersebut merupakan pondasi yang bagus untuk keberhasilan program.

Berdasarkan permasalahan tersebut, maka ditetapkan tujuan program KKN UAD adalah memberdayakan masyarakat Bausasran Yogyakarta dalam kepedulian lingkungan, kebersihan dan kesehatan.

\section{METODE}

Program KKN diiukuti oleh 27 orang mahasiswa. Untuk mencapai tujuan yang diharapkan, program KKN di Bausasran dilakukan dengan cara pemberdayaan masyarakat melalui pendidikan masyarakat, difusi ilmu pengetahuan dan teknologi dan praktek langsung. Waktu pelaksanaan dari tanggal 17 November 2017-17 Januari 2018. Ringkasan metode pelaksanaan beserta jam kerja efektif mahasiswa (JKEM) tersaji pada tabel 1. 
Tabel 1. Metode, Kegiatan, JKEM

\begin{tabular}{|c|c|c|c|}
\hline No & Metode & Kegiatan & JKEM \\
\hline \multirow[t]{5}{*}{1} & $\begin{array}{l}\text { Pendidikan } \\
\text { masyarakat }\end{array}$ & $\begin{array}{l}\text { Menyelenggarakan penyuluhan dan praktek } \\
\text { PHBS tentang cuci tangan }\end{array}$ & $1 \times 3$ jam \\
\hline & & $\begin{array}{l}\text { Mengadakan penyuluhan kesehatan di } \\
\text { posyandu bagi balita }\end{array}$ & $1 \times 2$ jam \\
\hline & & $\begin{array}{l}\text { Mengadakan sosialisasi pentingnya imunisasi } \\
\text { dan pemberian ASI untuk ibu-ibu }\end{array}$ & $1 \times 2$ jam \\
\hline & & $\begin{array}{l}\text { Mengadakan sosialisasi tentang cara } \\
\text { pengolahan dan pemilahan sampah organik } \\
\text { dan anorganik }\end{array}$ & $1 \times 1,5$ jam \\
\hline & & $\begin{array}{l}\text { Mengadakan penyuluhan kesehatan mengenai } \\
\text { psikologi lansia }\end{array}$ & $3 \times 2$ jam \\
\hline \multirow[t]{2}{*}{2} & Difusi iptek & $\begin{array}{l}\text { Menyelenggarakan pelatihan pembuatan } \\
\text { pupuk organik cair }\end{array}$ & $1 \times 1,5 \mathrm{jam}$ \\
\hline & & $\begin{array}{l}\text { Menyelenggarakan pelatihan pembuatan } \\
\text { yogurt }\end{array}$ & $1 \times 2$ jam \\
\hline \multirow[t]{5}{*}{3} & Praktek & Pelatihan pembuatan bros dari barang bekas & $1 \times 2$ jam \\
\hline & & $\begin{array}{l}\text { Pelatihan penyemaian dan perawatan bibit } \\
\text { TOGA }\end{array}$ & $2 \times 1,5$ jam \\
\hline & & $\begin{array}{l}\text { Pelatihan pengolahan sampah anorganik } \\
\text { (bank sampah) }\end{array}$ & $2 \times 2$ jam \\
\hline & & Pengolahan lahan kosong untuk TOGA & $3 \times 2$ jam \\
\hline & & $\begin{array}{l}\text { Mengadakan gotong-royong membersihkan } \\
\text { lingkungan }\end{array}$ & $3 \times 1,5$ jam \\
\hline
\end{tabular}

\section{HASIL, PEMBAHASAN, DAN DAMPAK}

Gambar aktivitas mahasiswa KKN UAD dengan pendampingan DPL beserta masyarakat Bausasran Yogyakarta dalam program peduli lingkungan, kebersihan dan kesehatan tersaji pada Gambar 4.

Dari gambar 4 terlihat program KKN di Bausasran Yogyakarta dapat terlaksana dengan partisipasi dan apresiasi masyarakat yang cukup tinggi dengan kata lain dapat memperdayakan masyarakat dalam program-program yang telah direncanakan. Dampak dari kegiatan $\mathrm{KKN}$ ini adalah : 1) tercipta kesadaran masyarakat sasaran tentang pentingnya PHBS , 2) peningkatan pengetahuan masyarakat dalam mengolah sampah, 3) tersedianya lahan hijau untuk produktifitas masyarakat, 4) tercipta kesadaran masyarakat tentang kebersihan dan kesehatan di lingkungan sekitar. 


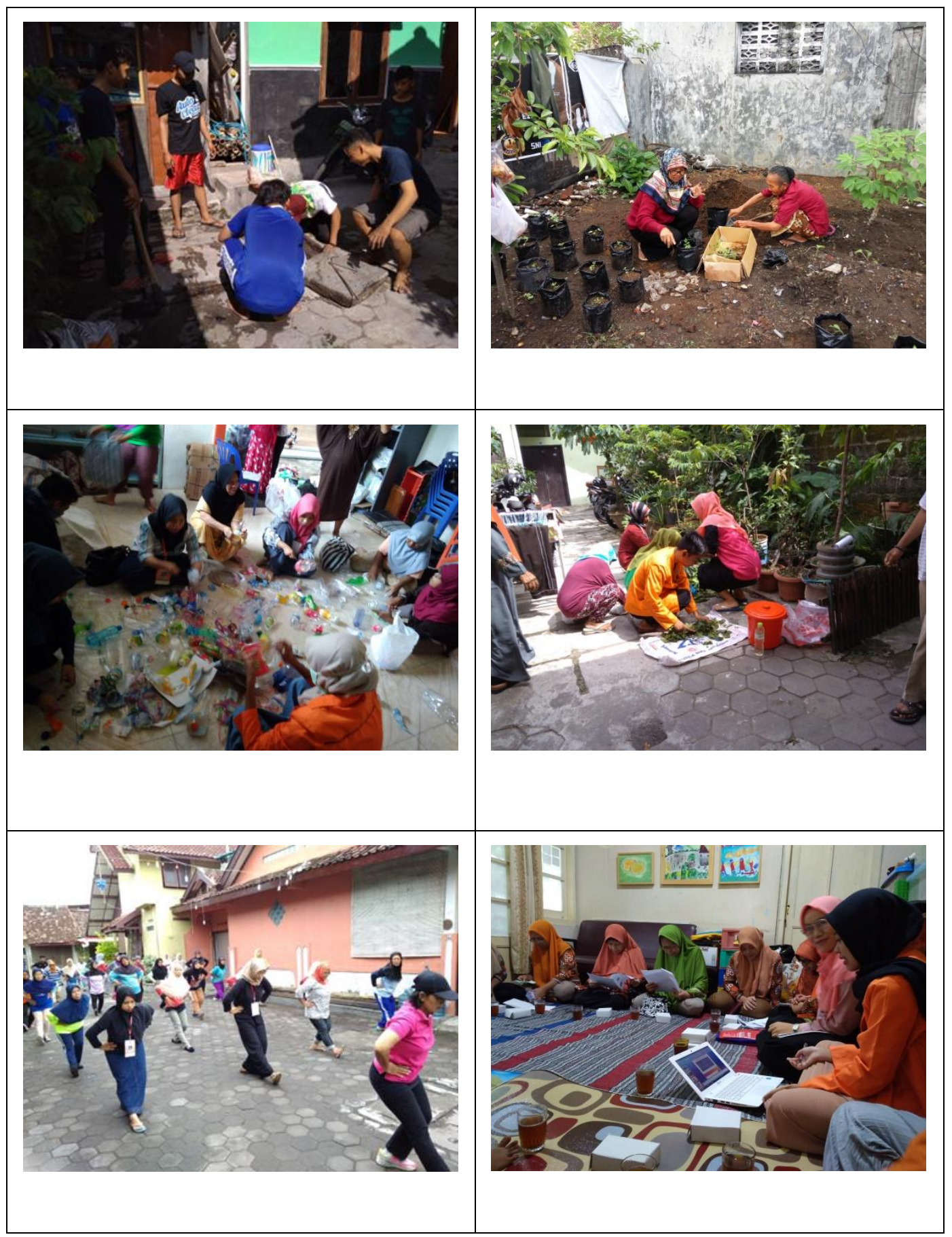

Gambar 4. Sebagian aktivitas mahasiswa KKN UAD dan masyarakat Bausasran dalam program peduli lingkungan, kebersihan dan kesehatan

\section{KESIMPULAN}

Program KKN UAD Bersama DPL dalam memberdayakan masyarakat Bausasran Yogyakarta dalam program peduli lingkungan, kebersihan dan kesehatan telah berjalan dengan baik. Kegiatan sukses terselengaran dan berhasil dalam memberdayakan masyarakat. 


\section{DAFTAR PUSTAKA}

Azwar A. 2005. Pengantar Ilmu Kesehatan Lingkungan. Jakarta: Penerbit Mutiara Sumber Widya Press.

Artiningsih, N. K. A., 2008. Peran Serta Masyarakat dalam Pengelolaan Sampah Rumah Tangga, Disertasi, Program Magister Ilmu Lingkungan Program Pasca Sarjana Universitas Diponegoro Semarang.

Syafrudin. 2004. Pengelolaan Sampah Berbasis Masyarakat.Prosiding, Diskusi Interaktif Pengelolaan Sampah Terpadu, Program Magister Ilmu Lingkungan Universitas Diponegoro, Semarang.

Wibowo A., Djajawinata D.T., 2004. Penanganan Sampah Perkotaan Terpadu. Diakses tanggal 17 Januari 2018, www.kkpi.go.id.

\section{Peraturan perundangan}

Peraturan Walikota Yogyakarta Nomor 5 Tahun 2007 tentang Pengelolaan Ruang Terbuka Hijau

Peraturan Walikota Yogyakarta Nomor 6 Tahun 2010 tentang Penyediaan Ruang Terbuka Hijau Privat 
2018 Jurnal Pemberdayaan: Publikasi Hasil Pengabdian kepada Masyarakat - ISSN: 2088 4559; e-ISSN:

Pemberdayaan Masyarakat Bausasran Yogyakarta ... (lis Wahyuningsih) | 142 